\title{
From Ambient Assisted Living to Global Information Management: IMIA-Referencing Publications in 2008
}

\author{
A. Geissbuhler', R. Haux², C. A. Kulikowski ${ }^{3}$ \\ ' University Hospitals of Geneva, Switzerland \\ 2 University of Braunschweig and Medical School Hannover, Germany \\ ${ }^{3}$ Rutgers - The State University of New Jersey, New Brunswick, NJ, USA
}

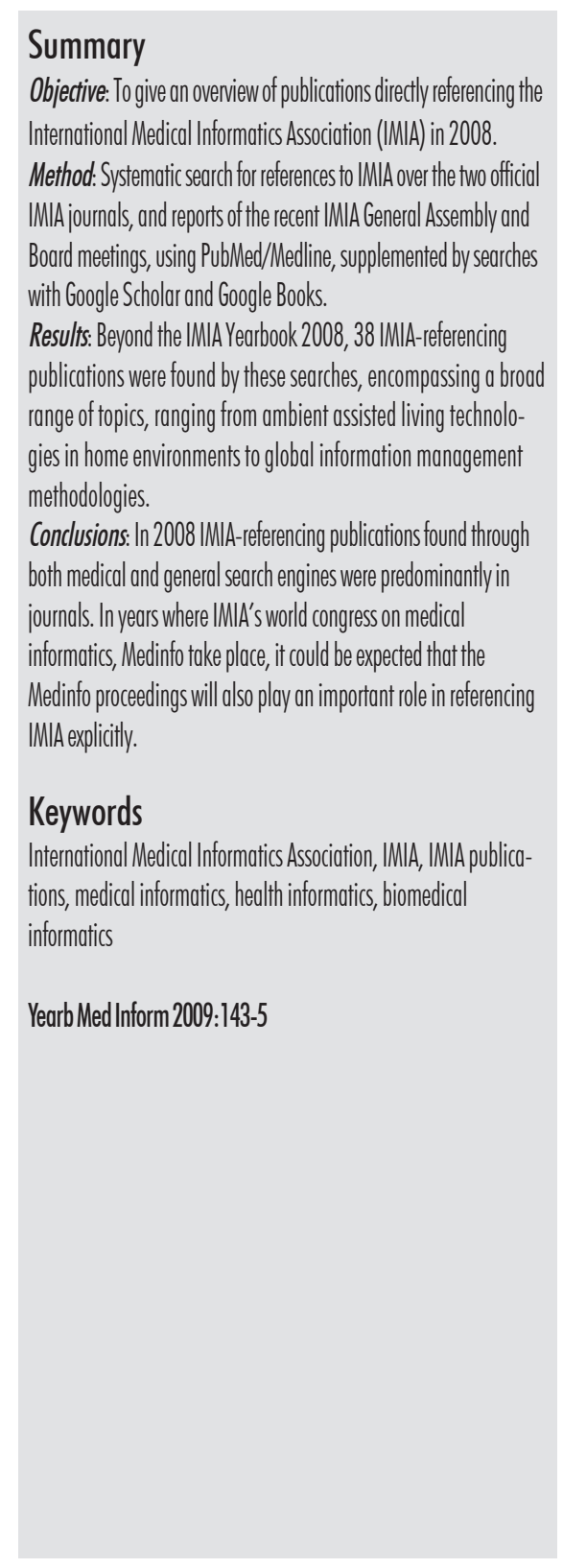

\section{Introduction}

IMIA - the International Medical Informatics Association [1] has a long and substantial publication history [2]. New knowledge in medical informatics often has been introduced and discussed in these publications. Of special relevance are the proceedings of the Medinfo congresses, IMIA's world congresses (from 1967) and those of other IMIA or IMIA-related conferences, the IMIA Yearbooks of Medical Informatics (from 1992) and publications in IMIA's official journals. In addition to the above-mentioned conferences, major sources for presenting and discussing new knowledge are meetings and working conferences of IMIA's working groups.

In order to make a record of such publications, the two current editors and a past editor of the IMIA Yearbook have decided to summarize them annually, starting with IMIA-referencing publications in 2008, to be documented in this Yearbook of Medical Informatics 2009.

\section{Methods}

To systematically identify IMIA-related publications we have searched:

- the two official IMIA journals, the International Journal of Medical Informatics (IJMI) and Methods of Information in Medicine (MIM);
- reports of the recent IMIA General Assembly and Board meetings, in particular in the reports of the IMIA Vice-President for Working Groups;

- PubMed/Medline, with the limitations a) publication year is "2008" and b) "IMIA" is in title, abstract or elsewhere;

- Google Scholar and Google Books, searching for IMIA.

All searches were done in May and June 2009. Articles, directly published in the IMIA Yearbook of Medical Informatics 2008, were not included in the searches, as they are all relevant, and the reader can directly refer to the Yearbook for them.

\section{Results}

For 2008 we identified 38 publications outside the IMIA Yearbook of Medical Informatics 2008. The majority of publications directly referring to IMIA were found in one of IMIA's official journals, MIM.

One of the fundamental goals of IMIA is to further the dissemination and exchange of knowledge, information and technology. Doing so involves the promotion of good practices in reporting evaluation studies in health informatics (STARE-HI, [3]), as well as the development of publications serving the evolving needs of our diverse community. For instance, a debate was initiated in 2008, discussing the neces- 
sity of a new journal or magazine, focussing on applications [4, 5]. Recently this has resulted in the creation of a new journal, Applied Clinical Informatics, about to be launched, and now endorsed by IMIA as an official publication.

Another key role of IMIA is to represent the medical and health informatics field with the World Health Organization and other international professional and governmental organizations [6]. In April 2008 the World Health Organization (WHO) organized a strategic planning workshop on the future of WHO's Global Observatory for eHealth. IMIA is non-governmental organization of WHO. IMIA members participated in this meeting. The outcomes of this WHO workshop was published in MIM issue 4 of 2008 [7]. Another report on IMIA's strategic plan in the context of global eHealth initiatives can be found in [8].

As a bridge organization, IMIA aims at promoting the cross-fertilization of health informatics information and knowledge across professional and geographical boundaries. Japan has a long and successful tradition in medical informatics, and the annual medical informatics conferences of IMIA's national member JAMI, the Japanese Association for Medical Informatics, are currently, to the knowledge of the authors, the largest national medical informatics conferences in the world. Probably because of language barriers, international journal publications referencing Japanese medical informatics developments (as well as those of other nonEnglish-translated proceedings in most other countries and regions, such as IMIA-LAC in 2008) are unfortunately relatively infrequent. In order to overcome this situation a special topic with selected papers from the Japanese Congress of Medical Informatics of 2007 has been published in MIM issue 6 from 2008 (introduction and overview in [9], research publications in [10] - [15]).

Leading the international medical and health informatics communities throughout the 21 st century, IMIA's working groups are exploring various domains of innovation. In 2008, a special issue edited by IMIA's working group on smart homes and ambient assisted living was published, considering a variety of aspects in the context of aging societies (introduction and overview in [16], research publications in [17] - [22]). Another issue of MIM contained a special topic on pervasive healthcare, with selected papers from a correspondingly named, and IMIAsupported conference (introduction and overview in [23], keynote paper in [24], research publications in [25] [33]), a theme also reported in other journals, highlighting the need for international research collaboration on health-enabling technologies for pervasive healthcare [34].

Informatics approaches to problems in nursing practice and organization have frequently involved the IMIA Nursing Informatics (NI) Group [35, 36], while the IMIA Code of Ethics is cited as a precedent for future globalization issues in health care [37], and the IMIA recommendations on education in health and medical informatics is cited in a review of pharmacy informatics syllabi in the US [38].

\section{Discussion}

2008 was a non-Medinfo year. IMIArelated publications were mostly found in journals. In Medinfo years, the Medinfo proceedings will of course also become an important source of IMIA-related references. Besides the publications in the IMIA Yearbook of Medical Informatics 2008, most IMIArelated publications were in one of the two official journals of IMIA, MIM. This has changed over the years, and can be expected to change in the future. With topics ranging from ambient assisted living technologies in home environments to global information management methodologies, the breadth in content was considerable.

The authors of this brief review have compiled a first set of direct, explicit references to IMIA and some of its 2008 activities from the literature. We expect to carry out a more comprehensive and systematic set of searches for 2009 and report on them in the 2010 IMIA Yearbook.

\section{References}

1. http://www.IMIA.org. Last access June 13, 2009.

2. Peterson HE, Hutter M. IMIA's Publication History. IMIA Yearbook of Medical Informatics 2007. Yearb Med Inform 2007:192-6.

3. Talmon J. Improving the quality of the evidence base of health informatics. AMIA Annu Symp Proc 2008 Nov 6:1211-2.

4. Lehmann CU, Altuwaijri MM, Li YC, Ball MJ, Haux R. Translational research in medical informatics or from theory to practice. A call for an applied informatics journal. Methods Inf Med 2008:47:1-3.

5. Ball MJ, Silva JS, Bierstock S, Douglas JV, Norcio AF, Chakraborty J, et al. Failure to provide clinicians useful IT systems: opportunities to leapfrog current technologies. Methods Inf Med 2008;47:4-7.

6. Kwankam SY, Geissbuhler A, Haux R. WHO and IMIA Issue Joint Communique. Inform Primary Care 2008:15:265.

7. Kay M, Santos J. Report on the World Health Organization Global Observatory for eHealth strategic planning workshop, April 2008. Methods Inf Med 2008;47:381-7.

8. Murray P, Haux R, Lorenzi N. eHealth and IMIA's strategic planning. In: Blobel B, Pharow P, Nerlich M, editors. eHealth: combining health telematics, telemedicine, biomedical engineering and bioinformatics to the edge, 15-20. Amsterdam: IOS Press (Stud Health Technol Inform. 134).

9. Tanaka H. Selected studies from current medical informatics research in Japan. Methods Inf Med 2008:47:511-2

10. Kawazoe Y, Ohe K. An ontology-based mediator of clinical information for decision support systems: a prototype of a clinical alert system for prescription. Methods Inf Med 2008; 47: 549-59.

11. Kimura M, Tani S, Watanabe H, Naito Y, Sakusabe $\mathrm{T}$, Watanabe $\mathrm{H}$, et al. High speed clinical data retrieval system with event time sequence feature: with 10 years of clinical data of Hamamatsu University Hospital CPOE. Methods Inf Med 2008; 47:560-8.

12. Nishimoto N, Terae S, Uesugi M, Ogasawara K, Sakurai T. Development of a medical-text parsing algorithm based on character adjacent pro international collaboration in the field of bability distribution for Japanese radiology reports. Methods Inf Med 2008;47:513-21.

13. Ishida H, Wong JB, Hino K, Kurokawa F, Nishina S, Sakaida I, et al. Validating a Markov model of treatment for hepatitis $\mathrm{C}$ virus-related hepatocellular carcinoma. Methods Inf Med 2008;47:529-40.

14. Suzuki T, Yokoi H, Fujita S, Takabayashi K. Auto- 
From Ambient Assisted Living to Global Information Management: IMIA-Referencing Publications in 2008

matic DPC code selection from electronic medical records: text mining trial of discharge summary. Methods Inf Med 2008;47:541-8.

15. Toyabe S, Miyashita A, Kitamura N, Kuwano R, Akazawa K. Prediction of disease-associated single nucleotide polymorphisms using virtual genomes constructed from a public haplotype database. Methods Inf Med 2008;47:522-8.

16. Demiris G. Smart homes and ambient assisted living in an aging society. New opportunities and challenges for biomedical informatics. Methods Inf Med 2008:47:56-7.

17. Blanson Henkemans OA, Rogers WA, Fisk AD, Neerincx MA, Lindenberg J, van der Mast CA. Usability of an adaptive computer assistant that improves self-care and health literacy of older adults. Methods Inf Med 2008;47:82-8.

18. Courtney KL. Privacy and senior willingness to adopt smart home information technology in residential care facilities. Methods Inf Med 2008; 47:76-81.

19. Fensli R, Pedersen PE, Gundersen T, Hejlesen O. Sensor acceptance model - measuring patient acceptance of wearable sensors. Methods Inf Med 2008;47:89-95.

20. Horwitz CM, Mueller M, Wiley D, Tentler A, Bocko $\mathrm{M}$, Chen L, Leibovici A, et al. Is home health technology adequate for proactive self-care? Methods Inf Med 2008;47:58-62.

21. Jakkula V, Cook DJ. Anomaly detection using temporal data mining in a smart home environment. Methods Inf Med 2008;47:70-5.

22. Rialle $\mathrm{V}$, Ollivet $\mathrm{C}$, Guigui $\mathrm{C}$, Hervé $\mathrm{C}$. What do family caregivers of Alzheimer's disease patients desire in smart home technologies? Contrasted results of a wide survey. Methods Inf Med 2008;47:63-9.

23. Saranummi N, Wactlar H. Editorial: pervasive healthcare. Selected papers from the Pervasive Healthcare 2008 Conference, Tampere, Finland. Methods Inf Med 2008;47:175-7.

24. Bardram JE. Pervasive healthcare as a scientific discipline. Methods Inf Med 2008;47:178-85.

25. Angius G, Pani D, Raffo L, Randaccio P, Seruis S. A tele-home care system exploiting the DVB-T technology and MHP. Methods Inf Med 2008:47:223-8.

26. Bidargaddi NP, Sarela A. Activity and heart ratebased measures for outpatient cardiac rehabilitation. Methods Inf Med 2008:47:208-16.

27. Kanai H, Nakada T, Hanba Y, Kunifuji S. A support system for context awareness in a group home using sound cues. Methods Inf Med 2008;47:198-202.

28. Kaushik P, Intille SS, Larson K. User-adaptive reminders for home-based medical tasks. A case study. Methods Inf Med 2008;47:203-7.

29. Laakko T, Leppänen J, Lähteenmäki J, Nummiaho A. Mobile health and wellness application framework. Methods Inf Med 2008;47:217-22.

30. Nöjd N, Hannula M, Narra N, Hyttinen J. Electrode position optimization for facial EMG measurements for human-computer interface. Methods Inf Med 2008 47:192-7.

31. Schumm J, Bächlin M, Setz C, Arnrich B, Roggen D, Tröster G. Effect of movements on the electrodermal response after a startle event. Methods Inf Med 2008;47:186-91.

32. Triantafyllidis A, Koutkias V, Chouvarda I, Maglaveras N. An open and reconfigurable wireless sensor network for pervasive health monitoring.
Methods Inf Med 2008;47:229-34.

33. Weerasinghe D, Rajarajan M, Elmufti K, Rakocevic V. Patient privacy protection using anonymous access control techniques. Methods Inf Med 2008; $47: 235-40$

34. Haux R, Howe J, Marschollek M, Plischke M, Wolf KH. Health-enabling technologies for pervasive health care: on services and ICT architecture paradigms. Inform Health Soc Care 2008;33:77-89.

35. Kennedy R, Newbold SK. The $1^{\text {st }}$ World Nursing Informatics Leadership Conference. Comput Inform Nursing 2008:26:62.

36. DuLong D Gassert C. Technology informatics guiding education reform: TIGER Phase2: Achieving the vision. Comput Inform Nursing 2008. 26: $59-61$

37. Kluge EHW. Ethical Aspects of Future Health Care: Globalization of Markets and Differentiation of Societies - Ethical Challenges. In: Blobel B, Pharow P, Nerlich M, editors. eHealth: combining health telematics, telemedicine, biomedical engineering and bioinformatics to the edge, 77-87. Amsterdam: IOS Press (Stud Health Technol Inform. 134).

38. Fox BI, Karcher RB, Flynn A, Mitchell S. Pharmacy Informatics Syllabi in Doctor of Pharmacy Programs in the US. Am J Pharm Educ 2008;72:89.

\section{Correspondence to:}

Antoine Geissbuhler

University Hospitals of Geneva

Division of Medical Informatics

Geneva, Switzerland

E-mail: antoine.geissbuhler@hruge.ch 